\title{
El giro kantiano en la Ética de J. L. Aranguren
}

\author{
PEDRO CEREZO GALÁN
}

No hay filósofo moral que se precie que no haya tenido que habérselas con Kant. Y esto no sólo por representar éticamente el punto de vista específico del hombre moderno en la conciencia moral, sino por haber fundado sobre ella una ética autónoma, exenta de metafísica y teología, erigiendo, a la vez, a la razón práctica en la clave de la existencia humana. Pasar por Kant, atravesar a Kant, superarlo en unos casos, volver a él en otros, se ha vuelto así una tarea inexcusable de la reflexión moral contemporánea. Se diría que Kant representa un puerto de alta montaña, que es preciso cruzar para abrirse a nuevos horizontes. o al que hay que volver, como a un refugio, cuando en medio del extravio hay necesidad de orientarse de nuevo y avizorar la ruta. $\mathrm{Ni}$ el sistema de eticidad hegeliano o marxista, ni la filosofía de los valores, ni la ética existencial, ni el análisis del lenguaje ético o la lógica de la argumentación moral son comprensibles al margen de los problemas y las tareas heredadas del kantismo. Inversamente a como, tras las ascesis kantiana de la metafísica, se sintió en el idealismo alemán la apremiante necesidad de atreverse a una experiencia más pregnante y rica de la realidad, en la quiebra del hegelianismo se hizo sentir, en sentido opuesto, la necesidad de un cambio de marcha en la vuelta a Kant. Esta oscilación es una constante en la historia de las ideas. La hartura del espíritu de sistema, ya sea metafísico o especulativo, reclama al espíritu crítico, como el exceso de astringencia impone la necesidad de superar la rígida aduana del criticismo. El pensamiento ético de José Luis Aranguren, como era de prever, no podía eximirse de la tarea de confrontarse con Kant, sin pecar de dogmático e ingenuo, pero lo que ya resulta realmente sorprendente es que, a lo largo de su trayectoria intelectual, se haya dado este doble movimiento de afelio y perihelio con respecto al kantismo. Alejado de Kant, en la elaboración de su programa mayor de ética, sustentada en cl doble principio antropológico y metafísico, e inspirada expresamente, como él mismo ha reconocido, en Aristóteles, Tomás de Aquino y X. Zubiri; próximo a Kant, sin embargo, cuando tras la cxploración de la crisis nihilista no encuentra otro oriente de su pensamiento. Poner de manifiesto este doble ciclo contrapuesto, que imprime a su obra como filósofo moral una tensión interna característica, va a ser el objetivo de este artículo. Dejo expresamente al margen todo juicio comparativo sobre el valor de estas etapas y, por supuesto, no pretendo en modo alguno erigir a una de ellas sobre la otra, e imponerla como definitiva, olvidando que ambas forman parte de un camino de pen- 
samiento, atravesado por una muy honda crisis ${ }^{1}$. De ahi que, a mi juicio, haya que buscar en esta crisis, en su vivencia y resolución, la clave decisiva para una hermenéutica integral de la obra de Aranguren.

\section{La cuestión del eticismo}

Kant ha sido, en efecto, uno de sus interlocutores privilegiados, incluso de primera hora, cuando el pensamiento ético arangureniano basculaba sobre la metafísica de X. Zubiri. En el Prólogo, treinta años después, a su Ética de 1958 recuerda Aranguren que

«si echamos una ojeada al índice de libros citados, advertimos que Heidegger es tanto o más mencionado que Zubiri (evidentemente, por la menor extensión de obra escrita de éste), y casi al par de él se cita a Kant» $(O . C$, II, p. 161).

Al margen de toda pretensión erudita, su diálogo con Kant en esta obra, y en gencral en todo el período que pudieramos denominar ético/sistemático, ha sido realmente decisivo. Kant aparece en los momentos de encrucijada, en que hay que tomar una u otra dirección -0 bien el giro copernicano hacia la «conciencia moral» o el ontológico hacia la «realidad moral»-. Y Aranguren adopta explícitamente el antikantiano. No podía ser de otro modo. En la medida que la Ética de Aranguren es una ética de base metafísica se ve obligada a enfrentarse con el kantismo. Pero había que añadir a éste otro motivo no menos significativo: en la medida, además, en que pretende ser una ética abierta a la religión, no sólo concorde con el cristianismo, sino más aún, exigitiva de una consumación religiosa. No es extraño, pues, que Kant aparezca en este primer período como representante arquetípico del formalismo y el eticismo moral, dos escollos que había que sortear en una Ética normativa objetiva de inspiración cristiana. Sería insuficiente atribuir en exclusiva este planteamiento a la dependencia discipular de Zubiri, tan fuerte en csta época, o bien a las corrientes filosóficas dominantes en círculos culturales próximos al catolicismo, con el prestigio ascendente de la filosofía de los valores y los intentos de una restauración escolástica de la metafísica, aledaños del pensamiento ontológico del primer Heidegger, aunque malentendiendo sus presupuestos. Ciertamente, el pensamiento filosófico continental era por aquellos años de mediados de síglo básicamente antikantiano. Tanto Scheler como Heidegger, por sólo citar a los nombres más sobresalientes, habían sometido al

' Creo que I. L. Aranguren no fue enteramente consciente de la profunda inflexión que la crisis iba a introducir en su pensamiento, pues cuando en 1983 echa una sumaria mirada sobre su obra se refiere tan sólo «al corrimiento hacia las cuestiones fronterizas» entre la ética y la política y la sociologia, «con un interés preponderantemente interdisciplinar, aun cuando con el acento puesto siempre en la moral» (Obras Completas, Trotta, Madrid, 1994-96, II, 563, edición todavia inconclusa: en lo sucesivo se citará por $O . C$.). 
kantismo, aunque por diversos motivos, a una profunda revisión. Max Scheler porque aspiraba a una ética normativa objetiva, no metafísica y abiertamente antiformalista. Heidedegger, en cambio, profundizando el formalismo kantiano en una dirección existencial, en su primera época, y abriéndolo finalmente a un «nuevo comienzo" ${ }^{2}$. Pero no era éste el caso de la posición de Aranguren. Más acá del nuevo platonismo de los valores y más allá del pensamiento ontológico-existencial heideggeriano, en un más allá que queria ser todavía explicitamente metafísico, la Ética de Aranguren se propuso ganar el suelo firme de la «realidad moral». Esta expresión debe entenderse en dos sentidos conexos y complementarios: ética de bienes, esto es, de reconocimiento y atenimiento a la dimensión perfectiva, que encierra la realidad, en cuanto sustentadora de la actividad del hombre, y, también, ética de la vida moral, del ethos como propone llamarla Aranguren, porque lo que al cabo importa no son los actos aislados, ni siquiera los hábitos, sino el todo de la vida buena (II, 162). Estas dos dimensiones, trabadas firmemente por Aranguren en una íntima alianza de impulso realizativo y utopía de felicidad, constituyen el secreto de su posición. En síntesis, y aun a riesgo de simplificar, para Aranguren la Ética es la reflexión metódica sobre el programa de la realización moral del yo. Ante todo, realización, pues cl hombre es una realidad inconclusa y, a la vez, per-ficienda, que tiene que hacerse con cosas y entre cosas, realizando sus potencias según la envergadura de sus posibilidades. Pero, además, moral, pues estas posibilidades deben ser preferidas en virtud de su valor intrínseco en orden a la consecución de la vida buena. Podría, en suma, afirmarse que la inspiración aristotélica era la más consonante con el talante y la actitud personales de Aranguren, por estos años de la década de los cincuenta. Actitud que no sólo era moral, sino preponderantemente religiosa, y por lo mismo - ya que me parece improcedente calificarla de optimista-, confiada y esperanzada, en una palabra, el «buen talante» (II, 634), que ni dura toda la vida ni puede estar nunca a nuestra disposición, y que en esta época lo identificaba él con el «catolicismo como modo de ser» (II, 634), huelga decir que un catolicismo bien templado, abierto y liberal, muy distante del cerril e intransigente que dominaba asfixiantemente en la España de aquella época.

Decía antes que se trata de una Ética de base metafísica. Aranguren prefiere llamarla de base antropológica, pues su auténtico punto de partida, en el orden del efectivo comienzo, es la estructura del comportamiento humano, relegando el principio metafísico, al que está subordinada, al orden de la justificación o validez del contenido (II, 225-26). En este sentido, tiene explicita conciencia de la singularidad de su posición, que difiere tanto de la metafísica-teológica de la Escolástica como de la trascendental kantiana,

${ }^{2}$ Sobre la Ética de Heidegger, puede verse mi trabajo «De la existencia ética a la Ética originaria», en Heidegger: la voz de tiempos sambrios, compilación de Félix Duque, Del Serbal, Barcelona, 1991, pp. 11-79. 
«todo lo cual significa que hemos prescindido de los puntos de partida usuales: el antiguo o escolástico, que arranca de la doctrina del fin último del hombre tal como viene ya formulado por la metafísica, y el moderno kantiano, que arranca del factum de la conciencia y pone en juego un positivismo de la introspección» (II, 349).

Creo que esta primera mención a Kant como «positivismo de la instrospección» es bien indicativa de por dónde iba a transcurrir, en esta primera etapa, la exégesis arangureniana del kantismo, viendo en él un riesgo de subjetivismo moral. Por lo demás, la calificación de ambos principios como antropológico y metafísico respectivamente, no me parcec cnteramente satisfactoria, al menos desde el punto de vista metodológico, pues la Antropología zubiriana que sirve de base al plantamiento de Aranguren no es menos metafísica que el llamado principio, éste sí reconocidamente metafísico, del orden objetivo de los fínes, según una legalidad ontológica, que se erige en regula morum.

De tratarse, por otra parte, de un principio meramente antropológico o psicológico, como lo llama en alguna ocasión, difícilmente habría podido escapar a la reducción psicologista, que con tanto ahínco combate. Esto no invalida en modo alguno su distinción entre moral como estructura y moral como contenido, pero ambas dimensiones caían en esta época del lado de la metafísica, esto es, suponían la existencia de un sujeto de realización y de una regla objetiva de lo bueno, inscritos en un plan ontológico de conjunto. Lo metafísico sería aquí, en sentido prekantiano, el expreso reconocimiento de que la libertad humana sólo es viable dentro de un orden objetivo, de modo que la autodeterminación alcanza valor moral en función de la jerarquía ontológica de estos fines. Sin esta presupuesta armonia del orden subjetivo de las potencias y el objetivo de los fines, no es posible mantener un programa consecuente de realización del yo. La dimensión estructural de la moral estriba en que el hombre es constitutivamente quehacer de sí, y se ve obligado a hacer su vida, a proyectarla, conducirla y configurarla, ateniéndose al principio de realidad; dicho zubirianamente, conforme a lo que las cosas son de suyo, según su índole propia, y claro está, conforme también a la propia índole de ser. «El hombre tiene que hacer este ajustamiento, tiene que iustum facere, tiene que justificar sus actos» (II, 207). Pero este dar cuenta de las preferencias y posibilidades puestas en juego remite a otro sentido de la justificación, no ya como ajustamiento, sino como justicia, según la terminología zubiriana, esto es, en conformidad con la medida del bien en sí. El tener que ajustarse a la realidad obliga, pues, a hacer justicia a lo que las cosas son en cuando fuente de posibilidades eligiendas, esto es, según su intrínseca medida de bien. «Justo ahora ya no significa simplemente ajustado, sino que significa honesto" (II, 208). Creo que no incurro en exageración al afirmar que la Ética de Aranguren de los años cincuenta era todavía una ćtica de la ley natural, con todos los matices y salvedades que se quiera en virtud de su modalización histórica, puesto que admite un momento normativo ontológico, que especifica tanto la bondad del fin del agente como la del objeto específico de su acto. Esto 
es lo que expresa el concepto ontológico de bien, como aquello que exige ser preferido en virtud de su adecuación con la pretensión realizativa y felicitaria del hombre. Por supuesto que este momento normativo está mediado por la conciencia, pero no descansa en ella, sino a la inversa, la conciencia moral recta es conciencia de lo que prescribe como universalmente válido en sí la ley natural:

«No, la conciencia moral no se dicta a sí misma las normas morales. Según vimos y veremos aún, la idea moderna de la conciencia, como la suprema instancia ética, no es más que una sustantivación del nous praktikós y de la conscientia escolástica, que aplica las normas generales a los casos particulares... El contenido de la moral, si bien es verdad que no viene simplemente de fuera, tampoco se lo dicta la conciencia soberanamente a sí misma, sino que se limita a aplicarlo mejor o peor» (II, 353-54).

Es esta soberanía de la conciencia lo que rechaza de plano en su Ética Aranguren. Cuando se atreve, en algún momento, a calificar la moral kantiana de «subjetivista» (II, 381) parece referirse a esta sustantivación de la conciencia, esto es, del sujeto moral, desvinculado de un orden normativo trascendente. La ética autónoma kantiana representa para él la culminación del proceso secularizador de la modernidad:

«La voluntad es selbstgesetzgebend, tiene que darse la ley a sí misma, y precisamente en esta autonomia de la voluntad y el entendimiento es en lo que ha consistido, a su juicio, lo positivo de la Ilustración» (II, 226).

Que las consecuencias extremas de este proceso sean para Aranguren el ateísmo ético de Sartre con su aceptación del absurdo expresan claramente hasta qué punto en la idea de autonomía estaba envuelta una pretensión de autarquía o de omnímoda disposición de sí. La crítica de Aranguren a la posición kantiana se polariza, en última instancia, en este punto. Es verdad que denuncia su formalismo vacío y su rigorismo extremo en la exaltación del deber, pero su punto de mira definitivo es el eticismo. Al formalismo le reprocha no sólo su incapacidad para determinar in concreto lo que en cada caso moralmente hay que hacer (II, 587), sino su seca abstracción, en términos que nos recuetdan la crítica de Scheler y Ortega, de reducir la vida moral al cumplimiento del deber:

«La moral no es cosa de la buena voluntad solamente, ni de meras obligaciones de conciencia, sino del hombre entero y, por tanto, de su inteligencia, de su conocimiento moral, de su pnidencia, hay que saber acertar, hay que, por ejemplo, realizar nuestra auténtica vocación» (II, 378).

Al trasfondo, como se ve, siempre queda la inspiración aristotélica acerca de la unidad de la vida buena. La comparación del formalismo kantiano con una forma de eplatonismo inmanentista, transposición del cielo estrellado al 
interior del hombre» (II, 318), reactualiza la crítica de Aristóteles a la univocidad platónica de la idea del bien, así como a su rígida separación entre lo inteligible y lo sensible, el mundo ideal y el de los impulsos y pasiones. $Y$ en cuanto al rigorismo -una de las críticas esgrimidas contra el planteamiento kantiano, ya desde sus inicios históricos como es el caso de Schiller-, Aranguren hace valer en su contra la constitutiva vinculación a la felicidad que hay en la naturaleza humana. La crítica radical de Kant al eudemonismo estuvo cicga para esta pretensión constitutiva del hombre, pues la felicidad no es otra cosa "que la aprobación última de nuestra posibilidad mejor» (II, 323). Por el contrario, «el deber es, por así decirlo - sentencia en otro lugat-, la cara negativa, coercitiva, obligatoria del bien moral» (II, 581). Ninguna obligación será incondicional fuera de esta primaria ligazón ontológica al bien. «Por ser la felicidad una posibilidad ya apropiada, el hombre está, como dice Zubiri, ligado a ella; en cambio, a las demás posibilidades - deberes- está obligado, ob felicitatem»

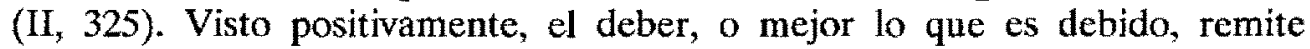
al bien como su condición ontológica đe posibilidad. El propósito es, pues, invertir la perspectiva kantiana, basada en «la tajante separación entre el orden del ser y el orden del deber ser», fruto, a su vez, de la inversión copernicana de la idea del bien, haciéndolo gravitar sobre la conciencia. Lejos de que el deber sea lo moralmente bueno, es el bien lo que hace que las cosas sean debidas propter felicitatem, en cuanto fuente de posibilidades, no sólo apropiables sino apropiandas, exigitivas en orden a la felicidad. Sería largo de discutir y no es del caso, si esta lectura tan secamente abstracta del imperativo categórico hace justicia a aspectos fundamentales del kantismo, como la postulación de un bicn integral para el hombre en la plena realización de sus disposiciones, o la misma exigencia de la felicidad para la determinación del bien integral. Pero pese a las posibles objeciones de detalle, es, con todo, innegable que el bien moral, en cuanto tal, no cstriba para Kant en la consecución de una vida felicitaria sino en el cumplimiento del deber en cuanto puro mandato de la razón.

Pero lo más decisivo, a mi juicio, y, desde luego, lo más original de la crítica de Aranguren a la posición kantiana hay que verlo en la idea de eticismo. El eticismo no es sólo la hipertrofia y sustantivación de lo ético, del puro deber-ser frente al orden del ser, sino la absolutización de la ley moral, en su estricta formalidad, o mejor aún, del sujeto de la ley, como instancia suprema y última del comportamiento. Es decir, en el eticismo, lo ético no es sólo lo autónomo con respecto a la metafísica, sino lo autárquico en la incondicionada voluntad de sí, voluntad de voluntad, como acertó a definirla Nietzsche, del sujeto soberano. Utilizando la doble fórmula zubiriana de la moral como justificación y justicia, podría decirse que, en el eticismo, la justificación del hombre por su propio esfuerzo hace surgir, desde sí y por sí misma, la justicia, esto es, la norma de lo que debe ser socialmente vinculante, en lugar de entender la justicia como el orden normativo de fines, independiente del sujeto, y cuyo 
reconocimiento es el principio de toda justificación. Kant representa, según Aranguren, el clímax del eticismo moderno, el momento de su madura conciencia y formulación en el primado de la razón práctica (II, 285), respetuoso todavía con el sentido religioso, aunque reducido a términos estrictamente morales. Pero la historia iba a llevar el principio eticista a sus conclusiones nihilistas extremas, tal como las formularon Nietzsche o Sartre. Interpretado desde la falsilla del proceso secularizador, el eticismo vendría a ser el voluntarismo antropológico de la ley, en correspondencia con el otro voluntarismo teológico de un Dios, que a fuer de omnipotente es arbitrario, y en cuanto tal pone la ley desde su absoluto e incondicionado querer. Los esfuerzos que pone Aranguren en reducir al absurdo la postura eticista, aun a costa de comprometer la autonomía del orden moral, son muy indicativos de su rechazo del relativismo y escepticismo, que se seguían, a su juicio, inevitablemente de la sustantivación de la conciencia moderna:

«Pero si desaparece Dios, todo se torna relativo e histórico y sólo puede subsistir la dimensión estructural de la moral, la moral formal del existencialismo, por ejemplo, pero no la moral como contenido» (II, 287).

Dejando al margen si el «Dios ha muerto» nietzscheano es una consecuencia histórica derivable, como piensa Aranguren, de la posición kantiana - lo que dista mucho de ser tan obvio como asegura-, es al menos innegable que con la ética autónoma de Kant no desaparece una fuente objetiva de justificación del contenido moral, pues justamente el imperativo actúa, en su puro formalismo, como un criterio decisivo del juicio moral acerca, no ya de lo que es universalizable en el orden de la acción, sino de lo que aspira a ser válido incondicional y universalmente. Aunque de la ley no se puede hacer derivar el contenido, que procede de los móviles subjetivos e intereses del mundo de la vida $-y$ en este sentido el imperativo es, en efecto, meramente formal-, puede, en virtud de su formalidad misma, enjuiciar el contenido real de la conducta, en tanto que instituye la forma incondicional de la razón en principio de lo universalmente válido. Por otra parte, Kant era consciente que aun no admitiendo un orden metafísico de fines, era posible reformular el imperativo categórico en el lenguaje de la finalidad, convirtiendo la forma de la razón en fin incondicionado del querer. El respeto a la ley es también el sentimiento de la propia dignidad como ser racional. Que el hombre sea el único fin en sí de la naturaleza significa que el entero reino natural debe estar subordinado a la perfección y felicidad del hombre. Pero al hombre en cuanto género ${ }^{3}$, como agrega muy sabiamente Kant, no del individuo, sino de la especie, pues la razón es de suyo una disposición genérica, que sólo se puede realizar en la comunidad de los hombres. $Y$ en cuanto tales seres racionales se toman los unos a los otros como fines en sí, sujetos a una legislación autónoma,

Kritik der Unteilskraft, pr. 83 . 
es pensable un enlace sistemático entre ellos según leyes, esto es, un reino de fines, que como prescribe el tercer tipo de formulación del imperativo categórico constituye el ideal incondicionado de la razón ${ }^{4}$. Si desaparece Dios no sólo «subsiste la dimensión estructural de la moral», como subraya Aranguren, sino la actitud moral - en el caso de Kant, el respeto a la majestad de la ley y a la dignidad del hombre-, donde se encierra un principio ético diamantino, que permite enjuiciar in concreto el contenido moral.

\section{El problema de la actitud ética}

Quisiera plantear a este propósito un problema, de cuya comprensión va a depender el resto. ¿No son lo mismo dimensión estructural y actitud moral? ¿O es acaso la actitud ética una instancia intermedia entre la moral como estructura y la moral como contenido, capaz por sí misma de compensar la indeterminación en que quedan las éticas formales con respecto a los contenidos concretos de la moral? Creo que la postura de Aranguren en este punto no es muy clara. En su Ética sostiene, en efecto, que hay lugar para distinguir, junto a los dos sentidos ya apuntados de moral como estructura y moral como contenido, «un tercer sentido: moral como actitud, es decir, actitud moral, actiud ética (eticista)» (II, 269). Llamo la atención sobre el añadido en paréntesis, tomando la actitud ética por eticista, ya que va a ser la clave del asunto. Se trata de uno de los pocos pasajes en que se establece en la Ética esta distinción, porque en general Aranguren la pasa por alto y recae de continuo en la distinción primera de moral como estructura y como contenido $6 A$ qué se debe este proceder? Podría afirmarse que Aranguren propende a englobar la actitud ética, en cuanto es un modo del comportamiento, dentro de la dimensión formal o estructural de la moral, con lo que la encubre, a mi entender, en su significación originaria. $Y$, de otra parte, la identifica siempre o casi siempre, como en este pasaje que se acaba de citar -me estoy refiriendo tan sólo a su Ética - con la actitud eticista, marrando así su verdadero sentido. Paradójicamente, se diría, después de proponer la distinción, lleva a cabo un doble encubrimiento de la actitud ética, polarizada en Kant, tanto a causa del formalismo como del eticismo. De ahí la escasa atención que presta Aranguren al tema en esta primera etapa de su obra, lo que le impide reconocerle a la actitud ética la función relevante que tiene en la vida moral. Como el equívoco es de gran alcance, conviene proceder con cautela.

Es indudable que la actitud ética tiene que ver con el comportamiento, en cuanto modo de hacer la vida o de conducirse en ella, pero esto no autoriza, a mi juicio, a incluirla en la moral como estructura. En sentido estricto, ésta sólo concicrne, como indica cl término, a la estructura antropológica de un

' Sobre la conexión intema entre los diversos tipos o figuras del imperativo categónico puede verse el locus clásico en la Gundlegung zur Metaphysik der Sitten, cap. 2. 
ser que consiste, en cuanto esencia abierta, incompleta o inconclusa, en autorrealización de sí por modo de libertad. Lo estructural del quehacer es de suyo neutro o indiferente con respecto al modo en que se lleve a cabo tal quehacer. Se llevará siempre de un modo o de otro, pero éste no se deriva necesariamente de la estructura ni es un momento de ella, pues en tal caso no podría convertirse en imperativo; en una palabra, lo estructural es pre-moral, como reconoce el mismo Aranguren, con respecto a la cualificación de lo honesto o deshonesto. Sería un contrasentido que se nos mandara ser auténticos, si resulta que toda vida ya $\mathrm{cs}$, estructuralmente hablando, un comportamiento en autenticidad. Como es un contrasentido que se nos mande ser libres, si uno ya lo es estructuralmente. La libertad no se puede mandar; la autenticidad sí. La actitud expresa, pues, una modalización del comportamiento, que positiva o negativamente concierne ya al orden moral ut sic. Ciertamente no indica qué hay que hacer, sino cómo hay que hacerlo, poniendo el énfasis en la forma del quehacer mâs que en el contenido, pero esta forma lo es de la moralidad, y en cuanto tal, establece la determinación originaria de lo bueno u honesto, no en razón del objeto, sino de la disposición. Es evidente que, incluso, en una ética orientada al contenido, la bondad de un acto no sólo se especifica por su objeto sino por la actitud moral del agente, de modo que de nada valdría, moralmente hablando, un acto virtuoso por su contenido que se hubiera ejecutado por motivos espúreos o en actitud farisaica. Como es obvio igualmente que cuando una ética formalista apela a la autenticidad, o a la "resolución» (Entlossenheit), o a «la vida en plena forma», está proponiendo un tipo de conducta moral en el sentido expreso de honesta o deshonesta, y no simplemente de conducta humana in genere. La consecuencia de estas distinciones es obvia: no pucde confundirse el plano estructural o formal de la moral con una ética formalista, que pone el acento en la actitud o en cómo existir moralmente. Ésta no se reduce al plano de la moral estructural, porque desatienda o se desentienda del contenido, antes bien determina un modo de habérselas con la realidad como específicamente moral. Dicho en otros términos, establece un imperativo, y por eso es propiamente moral y no simplemente comportamiento.

Pero sobre el equívoco de que todo lo que sea formal pertenece a la moral como estructura, se monta otro, no menos grave, de que lo formal del formalismo moral implica de suyo una actitud eticista. Es curioso y sintomático, por lo demás, como indicaba antes, que en el pasaje citado, en que se establece la distinción, un paréntesis añadido introduzca el equívoco de marras, al producir un deslizamiento de la actitud ética al eticismo, como si todo el sentido de la actitud ética estuviera dado, al modo de Kierkegaard, en su contraposición a la actitud religiosa. ¿No sería acaso ética una actitud abierta a la religión, como la que propugna Aranguren? ¿Por qué empeñarse en definir la actitud ética en términos de un eticismo excluyente o incompatible con lo religioso, cuando no lo fue ni siquiera el formalismo kantiano? Como Aranguren se 
atiene exclusivamente a esta contraposición, no es extraño que la actitud ética le quede escorada en un sentido eticista, implícitamente ateo, de autosuficiencia y endiosamiento (II, 270-71) y que, en consecuencia, trate de templarla o equilibrarla, abriéndola -cosa que a partir de tales supuestos sería poco menos que imposible - a la religión. Pero en la medida en que esta apertura sea posible desde ella misma, vendría a indicar simplemente que la actitud ética no implica de suyo una postura excluyente de signo eticista. El problema estriba, pues, en identificar la actitud ética en su sentido propio y originario, con anterioridad al juego kierkegaardiano de las contraposiciones. Creo que para este menester, Kant es un lugar privilegiado, pues en él aparece la actitud ética en su puridad, más allá de lo estructural y más acá del contenido, incluso superando definitivamente el concepto de una ley natural, pues ésta para el hombre sólo puede estar dada como ley de y en su razón, como la ley que expresa su propia naturaleza racional (Vermunftwesen), de modo que, incluso, para Dios la ley moral no puede ser otra cosa que la ley misma de la razón. La actitud ética consiste en el respeto a esta ley, fundado en la convicción interior, y no en la presión o el interés. No hay mejor modo de caracterizar a la actitud ética que por el principio de autonomía de la conciencia moral, en virtud del cual la naturaleza racional lleva en sí y es para sí la forma de la moralidad. Creo que éste es un descubrimiento kantiano imperecedero, de modo que a partir de Kant cualquier moral normativa, esto es, que pretenda ser objetiva y universal, sea cual fuere su origen, tendrá que pasar por la instancia de la conciencia moral. Tambiến una ética de los bienes, incluso del Bien supremo, tiene que comparecer ante la conciencia moral, como la instancia última de justificación. Ahora bien, puesto que la Ética de Aranguren, en virtud de sus presupuestos o condicionamientos metafísicos, se veía obligada a apartarse o distanciarse, en su punto de partida, del principio kantiano de la conciencia moral, por sospechoso de «subjetivismo», encubría fatalmente la dimensión de la actitud ética, asimilándola al eticismo.

\section{El punto crítico de retomo}

Será precisa la experiencia de una profunda crisis para que Aranguren pueda rectificar el rumbo. En modo alguno me refiero a una crisis personal, por muy hondos que fueran los efectos y resonancias en su propia vida, sino colectiva e histórica, de magnitud omnímoda y radical, que constituye el destino de nuestra época - «la nueva situación es bien descrita - escribe en 1962-con la palabra nihilismo. Nada de lo que daba sentido sobrenatural o espiritual a la existencia queda ya en pie» ${ }^{5}$ (II, 547). Crisis de tal envergadura no podía

\footnotetext{
'Implicaciones de la filosofia en la vida contemporánea, en $O . C$, , II, 541-560.
} 
haber pasado desapercibida en su Ética ${ }^{6}$, pero sólo a partir de los años sesenta va a ser objeto de una constante atención. $\mathrm{Y}$ es que no basta con esquivarla teóricamente con una muy poco conveniente reducción ad absurdum, pues justamente lo característico de la época, como dirá más tarde, es haber hecho del absurdo, de la instalación en la contingencia más radical, una forma de vida. Crisis de principios o fundamentos, como él la llama, que afecta a todo el ámbito de la cultura «en su forma más extrcmada y radical». Crisis, por tanto, y también de la metafísica, atenazada por el doble flanco de la crítica lingǘstica y el socavamiento heideggeriano del pensamiento representativo. $Y$ crisis a un tiempo religiosa, de desencantamiento del mundo, por utilizar la expresión de Max Weber, por pérdida de la dimensión mistérica y naufragio de la esperanza. En el ámbito de la ética, Aranguren bautiza la crisis como «desmoralización», en el sentido fuerte y radical de no saber cómo ni para qué vivir. No es sólo el "vacío moral» (value vacuum) (II, 600), la liquidación de los mores - creencias, valores y formas de vida, que habían estado secularmente vigentes-, sino de algo más profundo, la impotencia para hacerse cargo creadoramente de la situación. La desmoralización como actitud, «la pérdida de confianza en la empresa del quehacer colectivon (II, 611). Y la única terapia válida para el desmoralizado no es la prédica de una moral, tanto más lejana y solemne cuanto más profunda haya calado en él la crisis, sino la restauración del gusto o del sentido moral; es decir, hacerle ganar la confianza en sí mismo, no en un gran programa moral, sino a piezas sueltas y en pequeñas tarcas (minima moralia), procurando, en una palabra, moralizarlo o tonificarlo en y desde su actitud. No se trata de salvar una moral, sino de aprender a existir moralmente, asumiendo la decisión autónoma y responsable entre lo justo y lo injusto.

En su Ética ya había constatado Aranguren que las épocas de crisis son propias al repliegue interior (II, 230), y, por tanto, a la acentuación de la forma de la moralidad sobre el contenido:

«No ha habido, en rigor, más que dos éticas formales: la kantiana y la existencial. Ambas han surgido en épocas de profunda crisis religiosa, en épocas de desconfianza en cuanto al contenido de la moral, que, como hemos visto, cs inseparable de la religión» (II, 366).

Y en otro apunte relevante sobre "la moral social» recordaba de nuevo la conexión históricamente comprobablc entre crisis y retraimiento al fuero interno, donde poder estribar en medio de la bancarrota de la moral colectiva:

'Me refiero, en concreto, al tema del «ateísmo ético», que en la Ética del 58 es el exponente más claro de la crisis. En otra. ocasión me he ocupado de la significación y alcance de esta crisis, en «J. L. L. Aranguren: reformador moral en época de crisis» (Isegoria, núm. 3, 1991, pp. 80 y ss.). 
"Pero como en el fondo no se sabe a qué atenerse con respecto a la intocable moral anterior, se produce el deslizamento desde el plano de la realidad moral al plano de la conciencia moral (III, 540).

En este contexto era inevitable la mención de Kant, aunque todavía en términos equívocos, al atribuirle «una ética individualista, puramente atenida al tribunal interior de la conciencia moral» (II, 540). Indudablemente el término «individualista» está tomado aquí en estricta oposición al modelo de las éticas comunitaristas, como la de Hegel, pero con todo sigue conservando una connotación peyorativa, que recuerda demasiado los juicios vertidos sobre 0 , por ser más exactos, contra Kant en la Ética de 1958. Pero tan pronto como desconecte la idea de subjetividad moral kantiana del riesgo de individualismo, la dejará en franquía para una positiva apropiación. Y esto es lo que ocurre en lo que podríamos llamar su segunda navegación. Esta se anuncia claramente en la reflexión que viene a cerrar sus Propuestas morales:

«a crisis, según se ha visto, es sumamente grave. Pero lo más grave de todo -y lo más inmoral - sería cerrar los ojos ante ella, no querer reconocerla, negarla terca y torpemente. El contenido de la moral puede, en épocas de inseguridad y transición, tornarse cuestionable. Lo que al hombre verdaderamente moral nada ni nadic le puede arrebatar es la actitud ética» (II, 604).

El énfasis final, tan claro y rotundo, nos hace pensar en un paso decisivo en el planteamiento del problema, que venimos considerando. Tampoco a don Quijote, pese a sus derrotas y malaventuras, le podían quitar el esfuerzo heroico, donde residía, como en su buena voluntad, su inmarcesible valor moral. $Y$ es a esta forma pura de la moralidad a la que apunta aquí Aranguren. ¿Cómo se produce el viraje? Era de esperar que tras la exploración de la gravedad de la crisis sacara las consecuencias pertinentes. La idea de la metafísica, concebida como un sistema global, se le torna fundamentalmente problemática en un tiempo de tanteo, ensayo y fragmentarismo ${ }^{7}$. De otro lado, la posibilidad de vitalizar las dos morales mundiales, que por entonces aún gozaban de cierta aceptación, la moral cristiana y la marxista, tal como se propuso el mismo Aranguren, tendría que pasar, entre otras condiciones, por reganar la dimensión originaria del fuero interior; es decir, por dejar de ser morales sociológicamentc impuestas y empezar a actuar desde la convicción. Y es que lo que realmente está en peligro no es tanto una determinada moral, sino la actitud moral misma, la liquidación de la decisión moral en un mundo de conductas adaptadas subli-

'Tengo la impresión que sin hacerlo constar expresamente, que yo sepa, se produce en estos años un distanciamiento de los planteamientos de Zubiri, que están en la base de su Ética. Todavia en la conferencia de Venecia de 1962 lo cita elogiosamente, emparejándolo con los intentos de un «uso moderado de la razón, consciente de sus propios límites (II, 555), pero su creciente escepticismo sobre la posibilidad de una metafísica tenía que minar, por fuerza, su confianza en lo que habia representado la obra zubiriana. 
minalmente al imperio de lo positivo dominante. La vuelta a Kant parece imponerse ahora como la única dirección de marcha. Ya apunta inequívocamente en Moralidades de hoy y de mañana —un lúcido ensayo de exploración en el orden de los minima moralia de la vida cotidiana-:

«iQueda alguna posibilidad - se preguntaba alli- de encontrar una base a la moral? En la noción, que acaba de ser muy rápidamente criticada de «conciencia moral», algo parece haber de justo, aunque precario: la moral como Faktum (Kant)» (II, 305-6).

Pero es en los Anexos de 1983 y 1984 complementarios a Propuestas morales donde se indica expresamente. En ambos puede percibirse una reevaluación del kantismo, exento ya de cualquier connotación peyorativa, de tal modo que hasta la expresión de «formalismo», siempre usada con un acento negativo en oposición a la moral como contenido, se trueca ahora en la más justa y precisa de formalidad, esto es, de forma interna de la moralidad:

«La moral de Kant, que en su contenido seguía siendo la moral (o, mejor dicho, una moral) cristiana, continúa siendo válida en su pura formalidad, al menos parcialmente: el doble presupuesto de toda moralidad es su sentido categórico (y no meramente hipotético o interesadamente pragmático) y su universalidad -concreta - de Regla de oro, de un no querer y querer para los demás lo que, formalmente, es claro, no queramos y queramos, respectivamente, para nosotros mismos» (II, 606).

Todavía se perciben en los textos algunos reparos o vacilaciones, como muestran las expresiones «aunque precario», o bien «al menos parcialmente», pero el clima ya es enteramente distinto al de la Ética. Y, por si quedara alguna duda al respecto, cn cl citado Anexo de 1984 no sólo constata Aranguren el repliegue ético que ha producido la crisis, sino que reivindica expresamente, en medio de la desorientación, la vuelta a Kant:

«Y como consecuencia de ello se produce un repliegue ético, cuyo iniciador fue Kant, desde el contenido a la forma de la moralidad. Si, aunque sólo sea por un momento, distinguimos entre moral (estructura, forzosidad de tener que hacer -quehacer- la propia vida) y moralidad (precepto, deber de hacerla de una determinada forma), entonces hay que decir, volviendo a Kant, que lo único bueno sin limitación es la buena voluntad, o dicho con lenguaje más actual, la moralidad en tanto que moral como actitud. Y ¿cuál es la autónoma guía de ésta? La conciencia moral» (II, 613).

Me he permitido citar estos textos con amplitud para que mejor se aprecie la envergadura de un cambio, que afecta incluso al lenguaje. No sólo menciona a Kant, con su giro copernicano hacia la conciencia, sino que se lo apropia, en una nueva dirección de marcha, Si la moral, en cuanto estructura, es quehacer en libertad, la moralidad significa la asunción responsable y consciente de esta libertad como autonomía en la dirección de sí. Ésta es la actitud moral. $\mathrm{Al}$ margen de todo eticismo, la actitud se perfila aquí como «la buena voluntad», 
donde reside, al decir de Kant, el «único valor interno absoluto». «Es buena sólo por el querer, es decir, es buena en sí misma» ${ }^{8}$. Pero la guía de esta buena voluntad no es otra que el principio autónomo de una legislación universal; en suma, la vuelta a la conciencia moral.

\section{La reivindicación de la actitud moral}

De la radicalidad del viraje habla muy elocuentemente la eliminación de la cuestión del eticismo. Como se ha indicado, a Kant se le había hecho en la Ética responsable del eticismo moderno y precursor, por tanto, del nihilismo de la cultura contemporánea. Desde estos presupuestos, el repliegue a Kant sólo podía significar, por tanto, una involución subjetivista, y hasta individualista, en línea con las consecuencias relativistas y escépticas. Ahora, en cambio, se cifra en el repliegue nada menos que la posibilidad de salvar la actitud ética en una época de omnímoda desmoralización. Obviamente, tales planteamientos no son compatibles. El Kant de la segunda época de Aranguren nada tiene que ver, a mi juicio, con el que había sido criticado desde los supuestos de la metafísica de Zubiri. Es verdad que la vuelta no se hace sin ciertas cautelas, pero son puramente verbales. En su giro hacia Kant, Aranguren suele preferir a los términos más secamente convencionales de «ley moral», «imperativo» o «deber», con los que había polemizado en su Ética, los más asépticos y con más vaga resonancia kantiana de faktum moral y postulado. $\mathrm{Y}$, sobre todo, al término «conciencia moral» superpone el de actitud. Creo que este cambio scmántico es muy significativo de que el acento se pone ahora, más que en la formalidad moral, en la fuerza moral, en cuanto principio dinámico de la resolución. No es que se excluya la formalidad misma de la autonomía, sino más bien se la ve como una exigencia interior que hay que vivir por dentro, en confrontación permanente contra los riesgos de cierre o bloqueo, por presión, inercia o acomodación, de la experiencia moral. Aranguren es muy consciente del peligro de atonía moral, que representa la insaciable sed de consumo de la sociedad tecnológica moderna, aque no deja lugar para la otra, para la genuina sed, también inextinguible, la representada por la actitud moral» (III, 552). En tiempos de extrema penuria y desmoralización, lo que más importa no es salvar una determinada moral, en lo que respecta a su contenido axiológico, sino la disposición moral en sí misma, esto es, la actitud. Ésta implica a la conciencia moral, y en cierto modo la reduplica. No es sólo sentido moral, sino valor moral, conciencia de ley y disposición activa hacia ella:

«La actitud moral lo es siempre de exigencia y de autoexigencia, de sed de justicia, de búsqueda e inquietud, de inconformismo y crítica del código moral vigente que, por perfecto que parezca, es siempre perceptible, y de propuesta, a veces sólo balbuciente, de un orden moral mejor» (III, 543).

\footnotetext{
${ }^{8}$ Grundlegung zur Metaphysik der Sitten, cap. 1.
} 
Pero, además, esto supone que la formalidad moral no está reñida formalísticamente con el contenido, sino que es más bien un principio de autoenjuiciamiento del contenido moral, sea éste cual fuere por su origen, y de autentificación de la experiencia moral. Desde luego, lo que de veras importa a Aranguren sigue siendo la vida moral, pero contemplada ahora desde la actitud ética, que la mantiene abierta y exigente en una tarea de depuración y renovación. En una palabra, la moralización o regeneración moral de la existencia, reconquistando de nuevo, a contracorriente e intempestivamente, la actitud ética. Ésta es la tarea de una época, que ha sido tocada de veras por la experiencia del nihilismo:

«Época ya no de Revolución, con mayúscula, pero sí de re-moralización, es decir, de recuperación de la actitud moral y de confianza, frente a la violencia y la agresión, en el lenguaje de la razón para la rcsolución de los conflictos a través de la comprensión del punto de vista del otro, en el diálogo, y del establecimiento de una sociedad de auténtica comunicación moral y no simplemente material» (II, 616).

¿No es esto acaso la abreviatura de un nuevo programa de ética, que se aparta bastante, no ya en la letra, me atrevería a decir que en el espíritu, del formulado en la Ética de 1958? Para tan vasto empeño, Kant podía brindar una guía de orientación ¿Qué debe entenderse, en este contexto, por moralización? Ante todo, la autentificación de la conducta moral, asumiêndola por modo reflexivo y personal. Antes de realizar determinados valores morales $o$ atenerse a los ya vigentes, importa existir moralmente, esto es, vivir en de-cisión moral, en justificación de las propias opciones de existencia. No se trata de inventarse una nueva moral original, sino de dar cuenta de aquella en que se vive y poder superat sus insuficiencias y limitaciones. De ahí la necesidad de un criterio incondicionado del juicio moral, que no es otro que la conciencia de la ley. La moralización contiene una doble dimensión, crítica y utópica, que corresponde a las dos caras del juicio moral, que es tanto principio crítico de enjuiciamiento de la propia experiencia como principio heurístico, a la vez, de nuevos contenidos morales. Consiste, pues, de un lado, en revisión de los mores o formas de vida, en que se está, y del otro, en alumbramiento de nuevas posibilidades de comportamiento (cfr. II, 588-89) ${ }^{9}$. En suma, es tanto «crítica del presente» como «creación del porvenir» (III, 307). Y en esta medida, vida moral, que se hace y se configura a sí misma, se narra e interpreta al filo de sus acciones - sigue, pues, siendo ethos o carácter moral-, pero la clave de la nueva hermenéutica no está tanto en la fuerza felicitaria de los proyectos, sino en el carácter autónomo -crítico y utópico a la vez- de la propia experiencia moral.

Ahora bien, esta justificación no se lleva a cabo sólo para uno mismo, sino con el otro y ante el otro, por la necesidad de dar cuenta de la propia

\footnotetext{
${ }^{9}$ Véase igualmente, III, 560-61, en la contraposición del intelectual y el político.
} 
opción moral. Esto es tanto más apremiante cuanto que en la sociedad contemporánea no se da un horizonte homogéneo de moralidad. $Y$, sin embargo, la vida política implica siempre, en varia medida, opciones morales, cada vez más finas y ajustadas según se complican nuestros poderes técnicos sobre el conjunto de la naturaleza y sobre los otros hombres. Tal como recuerda Aranguren,

«la sociedad moderna tiende a constituirse como sociedad abierta (aunque nunca llegue a serlo completamente): el código moral vigente no se presenta ya como intocable, sino como susceptible de modificación. En segundo lugar, la sociedad verdaderamente abierta es pluralista y, por tanto, rigen en ella una pluralidad de códigos morales» (II, 588).

En tales circunstancias, la solución no estriba en reforzar los códigos morales, enquistándolos en tradiciones herméticas, sino en abrirlos y confrontarlos, en una mediación inacabable. La sociedad abierta requiere una ética cívica en permanente tarea de justificación:

«En ella el acuerdo moral sólo puede proceder del consenso racional y libre, de la sustitución de cualquier clase de heteronomía o imposición, de cualquier clase de violencia, no sólo la violencia fisica, por el lenguaje y el diálogo» (II, 614).

$Y$ de nuevo aquí la remisión a Kant se impone de modo inexcusable. La dimensión cognitiva y argumental de la Ética resulta imprescindible. Ser moralmente responsable es poder dar cuenta de las propias opciones de valor, en la medida en que éstas encierran una pretensión de universalidad. La cuestión de la valide $z$ cobra así, en un tiempo de pluralismo cultural y relativismo moral, un alcance insospechado. En este sentido, la Ética, como recuerda Aranguren, «necesita ser siempre razonamiento» (II, 595). No puede atrincherarse en la propia conciencia ni apelar al sentimiento moral. Mucho menos puede recurrir a la mera persuasión emotiva sin injuriar con ello a la propia dignidad del hombre, pues en cuanto ser racional (Vemunftwesen) exige que se le hable a su razón. Ha de comparecer, pues, en la vida pública en el lenguaje de la convicción racional, que puede argumentar en pro de sus opciones de valor y reclamar por ello el libre asentimiento. Ciertamente que Aranguren no ha explorado el campo de juego, las aporías y cuporias de una tal ética dialógica o de la comunicación, como hoy se la llama, pero ha indicado, al menos, las condiciones que sustentan su posibilidad. Y, como no podía ser de otro modo, el imperativo kantiano reaparece en el trasfondo, como su actitud posibilitable:

«Su punto de partida es el respeto al valor moral de la persona, a la dignidad del otro. No un valor fríamente rcconocido, sino por el que debo ser afectado en la doble acepción de sentir afecto moral por el otro en tanto que otro, y de sentirme afectado por lo que dice, por su punto de vista, por su parte de razón moral» (II, 614). 
Pero si bien se repara, no es sólo la actitud moral, sino la misma forma de la moralidad la que entra en juego. Para hacer posible el diálogo entre códigos morales, al menos a primera vista inconmensurables por la diversidad de sus premisas axiológicas, sería necesario un principio ético meta-moral, en su misma formalidad, y en este sentido, trascendental, pues ha de trascender, en efecto, todo contenido axiológico determinado, toda moral como contenido, como condición para poder fundarlo o posibilitarlo en un diálogo mediador interminable. Tal es el sentido del imperativo kantiano, que no es vacío por defecto de su formalismo sino por exigencia de su trascendentalidad. Y ésta es la tarea ética, kantiana en su inspiración, que, según Aranguren, tiene nuestra época por delante:

«En la actualidad no es posible todavía una síntesis de esta pluralidad moral. La tarea a nuestro alcance es hoy por hoy, desde el punto de vista teórico, lograr la comunicación entre los supuestos de las diferentes morales y, desde el punto de vista de la praxis, mantener la solidaridad, principio esencial de toda moral» $(\mathrm{II}, 606)$.

Pero, mientras tanto, y en tanto que se recorre este camino de suyo interminable, porque el propio camino representa una idea ética de realización infinita, será inexcusable, ahora y siempre, salvar la actitud. En ésta se encierra la fuerza moral genuina para resistir al mal. Para resistir y para alumbrar el futuro. Más que formal/formalista, considerado el kantismo desde el carácter dinámico de la actitud, se muestra como una ética abierta, expansiva y solidaria, dotada de élan moral o ímpetu renovador, crítico y utópico un tiempo, capaz de sintonizar con la sociedad pluralista posmoderna, que ha de ser, si quiere subsistir, ante todo abierta, si no la cierra la inercia, la presión o el conformismo.

Hasta aquí he contado una historia, espero que bien fundada, algo así como el escorzo kantiano de una biografía intelectual. Todo el quid de la cuestión, del afelio y perihelio al kantismo, como lo llamé al comienzo, está, como creo haber mostrado, en la experiencia del nihilismo. Pero llegado a este punto me surgen preguntas inesquivables. ¿Fue suficiente su dilucidación del nihilismo? ¿Se engañaba Aranguren al cifrar en la ética kantiana tantas esperanzas? $O$, en otros términos, ihabía hecho una lectura en profundidad de la crisis nihilista como para ver en la vuelta a Kant un puerto de orientación? Se trata, por lo demás, de preguntas excesivas, cuando menos, en el obvio sentido de que exceden los límites de este artículo. Desde luego, no creo que fueran preguntas que tuviera resueltas Aranguren, al menos teóricamente, porque la re-solución práctica era otra cosa, la más afín con su actitud, paradójicamente escéptica y esforzada a la vez, de moralista. De moralista en tiempos de crisis, que fue lo que real y verdaderamente quiso ser. 